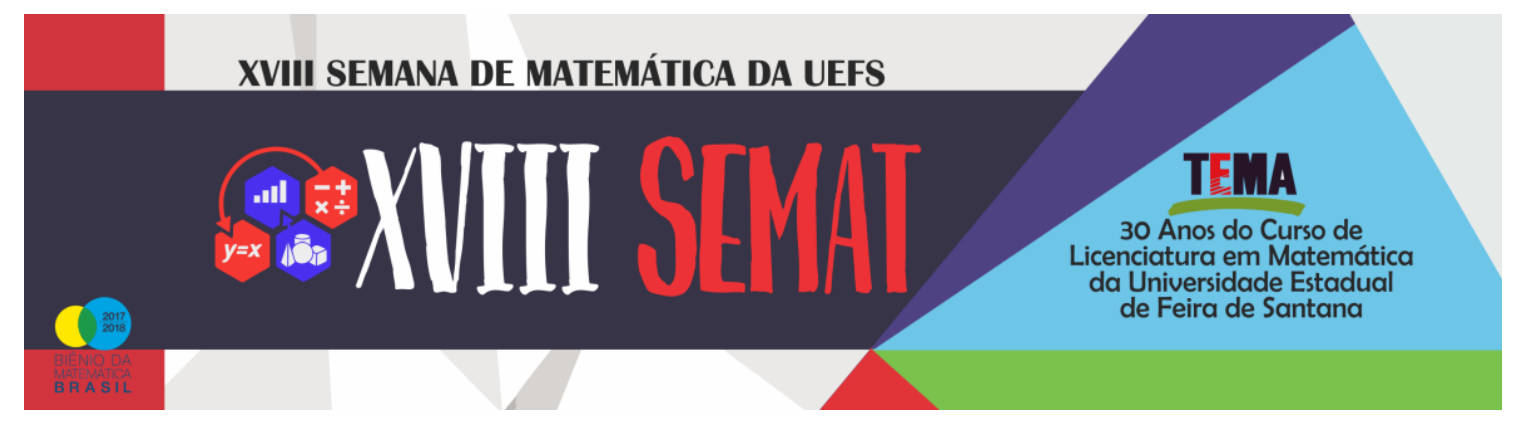

\title{
ELEMENTOS PARA A HISTÓRIA DA MATEMÁTICA EM FEIRA DE SANTANA: ALGUMAS CONTRIBUIÇÕES DO PROFESSOR CARLOMAN CARLOS BORGES
}

\section{EIXO TEMÁTICO: ASPECTOS HISTÓRICOS, FILOSÓFICOS E CULTURAIS DO ENSINO DE MATEMÁTICA}

\author{
Leila Islânia de Oliveira ${ }^{1}$ \\ Ana Maria Fontes dos Santos ${ }^{2}$
}

\section{Resumo}

Neste artigo trataremos sobre a trajetória do professor Carloman Carlos Borges na constituição da história da educação matemática em Feira de Santana. Para atingir este objetivo, partiremos do mapeamento sobre a contextualização histórica da educação matemática na Bahia, seus atores principais, ambiente no qual interagiu e formou-se o professor Carloman, que recebeu influência do matemático Omar Catunda. A criação da Faculdade de Educação em Feira de Santana trouxe o referido prof. para a cidade, sendo um dos principais agentes na implantação dessa Faculdade e, posteriormente, no curso de Matemática da Universidade Estadual de Feira de Santana. Os dados aqui utilizados resultam de pesquisa bibliográfica, entrevistas com dois ex-alunos e levantamento direto efetuado junto ao Núcleo de Educação Matemática Omar Catunda (NEMOC), da Universidade Estadual de Feira de Santana (UEFS).

Palavras-chave: história da educação; educação matemática na Bahia; formação de professores.

\section{Introdução}

Este trabalho faz parte do projeto de pesquisa "Memórias da educação na Bahia em tempos de ditadura (1930 a 1985)”, desenvolvido pelo Núcleo de Estudos e Pesquisa em História da Educação (NUHEB) e, especificamente, faz parte do plano de trabalho de

\footnotetext{
${ }^{1}$ Estudante do Curso de Licenciatura em Matemática da Universidade Estadual de Feira de Santana: leilaislaniaoliveira@gmail.com

${ }^{2}$ Professora Adjunto do Departamento de Educação da Universidade Estadual de Feira de Santana: anamaria_fontes44@yahoo.com.br
} 
iniciação científica "Trajetória de vida: o professor Carloman Carlos Borges e o ensino da matemática na região de Feira de Santana (1968-1980)", que tem como um dos objetivos construir um documentário sobre aspectos da trajetória do referido professor no período em foco. Neste sentido, apresentamos aqui dados parciais da pesquisa em curso, referentes ao estudo bibliográfico, entrevistas prévias e do levantamento junto ao NEMOC.

Assim, para situarmos a educação matemática em Feira de Santana apresentamos, inicialmente, aspectos da trajetória de implantação da mesma na Bahia, desde a Faculdade de Filosofia da Bahia e depois na Universidade da Bahia, conforme o trabalho de Dias (2002; 2012) especificamente no período de 1930 a 1970, cujos desdobramentos resultaram na criação do Instituto de Matemática da Universidade Federal da Bahia (UFBA). Sobre a caminhada da implantação do primeiro curso de Matemática em Feira de Santana usamos a literatura produzida por Ferreira (2017) e Santos (2016), bem como dados coletados por Santos (2015), com o objetivo de contextualizarmos as contribuições do professor Carloman no cenário da história da matemática em Feira de Santana. Conforme o estudo realizado neste trabalho, a mesma vincula-se à história da formação de professores local, que visava preparar as populações trabalhadoras do município e região para atender aos objetivos de expansão da economia interiorana naquele período de ditadura.

\section{Aspectos históricos da Matemática na Bahia}

Um marco importante na implantação dos estudos específicos voltados para o ensino da ciência matemática foi a criação de Faculdades de Filosofia (FF), no bojo do processo de criação das principais universidades brasileiras ${ }^{3}$, postas em funcionamento desde o início da década de 1930, todas elas criaram Faculdades de Filosofia, que passariam a ser o local da formação de professores para o atual ensino médio. Naquele momento, criar Faculdade de Filosofia foi uma das exigências postas pelo "Estatuto das Universidades", de 1931, para que se criassem universidades.

Até esse período o ensino da matemática era protagonizado por profissionais que não tinham a formação específica. Segundo Dias (2012), os matemáticos, os professores da matéria e as pessoas que dominavam algum conhecimento da área, geralmente eram engenheiros civis

\footnotetext{
${ }^{3}$ Universidade do Distrito Federal (UDF), criada por Anísio Teixeira; Universidade de São Paulo (USP); e Universidade do Brasil (UB), esta implantada no Estado Novo.
} 
ou militares, que se bacharelavam ou se doutoravam nessa ciência. O referido autor salienta que escolas politécnicas e as academias militares, ao mesmo tempo em que formavam engenheiros, também centralizavam a produção e a difusão da matemática da época.

As faculdades de filosofia, portanto, foram os locais onde começaram a funcionar os primeiros cursos superiores de matemática e de outras disciplinas. Nessas instituições além do objetivo de formar profissionais especializados para a atuação no ensino ocorreu também o desenvolvimento da pesquisa. Diante desse novo cenário, Dias (2012) afirma que a matemática passou por transformações em todo o Brasil, não só ganhou novos espaços institucionais, como também uma nova posição científica e social. De acordo com Dias (2002), uma das principais metas da FF foi de fato, a formação especializada dos professores em um curso de nível superior e, nesse sentido, a FF tinha como missão preparar professores para o ensino secundário (atual ensino médio) e cooperar no desenvolvimento da cultura. Assim, foi criada na Bahia, ainda no primeiro ano da década de 40, a Faculdade de Filosofia Ciências e Letras (FFCL) da Bahia, que seguia o modelo curricular vigente em todos os cursos do país, conforme o estabelecido pela Faculdade Nacional de Filosofia (esta fazia parte da Universidade do Brasil, UB, criada durante o Estado Novo). Diversos foram os cursos implantados na faculdade baiana (total de doze), conforme se constata nos termos do Decreto $\mathrm{n}^{\circ} 10.664$, de 20 de outubro de 1942, que autoriza o funcionamento da referida Faculdade, são eles: "de filosofia, matemática, física, química, história natural, geografia e história, ciências sociais, letras clássicas, letras neo-latinas, letras anglo-germânicas e pedagogia”4.

O formato básico dos referidos cursos era dividido em duas partes, a primeira constituída pelas disciplinas científicas propriamente ditas, tinha duração de três anos e atribuía o título de bacharel, já a segunda, era composta pelo curso de didática, com duração de um ano e concedia o título de licenciado. Ainda em conformidade com Dias (2002), o curso de didática foi um marco muito importante para a formação dos professores de matemática, visto que estes profissionais não recebiam nenhuma formação didática, e a grande maioria das pessoas que ministravam as aulas de matemática foram formados em engenharia, pela Escola Politécnica. $\mathrm{O}$ autor também registra que a primeira turma de bacharéis em matemática formou-se em 1945.

\footnotetext{
${ }^{4}$ In ROCHA, J. F. M. História do Curso de Física da UFBA: da Faculdade de Filosofia da Bahia à contemporaneidade Revista Brasileira de História da Ciência, Rio de Janeiro, v. 9, n. 2, p. 265-287, jul | dez 2016 (p.268).
} 
Observe-se que no ano seguinte, 1946, foi criada a Universidade da Bahia (UBa), que agregou a FFCL, provavelmente, coincide com o mesmo ano de formação dos primeiros licenciados em matemática da Bahia.

De acordo com o trabalho elaborado por Dias (2012), alguns professores assumiram papéis importantes na construção da história da matemática na Bahia: as professoras Martha Maria de Souza Dantas e Arlete Cerqueira de Lima, que construíram um legado a partir da FFCL da Universidade da Bahia e o professor Omar Catunda cuja trajetória acadêmica está relacionada à criação da Faculdade de Filosofia da USP.

Por ordem cronológica, a primeira a destacar-se foi Martha Dantas, concluinte do bacharelado de matemática da FFCL em 1948 e, na sequência, dirigiu o Ginásio de Aplicação da referida Faculdade. Poucos anos depois, em 1952 tornou-se professora de Didática Especial da Matemática. De acordo com o autor acima citado, as habilidades linguísticas da professora em foco (dominava mais de um idioma), foram essenciais para colocá-la em contato com a produção europeia e americana da época, acerca das inovações que estavam sendo implantadas nos outros países, pois naquele período o ensino tradicional da matemática começava a ser substituído pela matemática moderna. Além disso, seu deslocamento para realização de estágios em países da Europa ${ }^{5}$ a incentivou a organizar com professores da FFCL e colegas de outros estados o I Congresso Nacional de Ensino de Matemática no Curso Secundário, em Salvador, ocorrido em 1955.

Dias (2012), argumenta que o congresso realizado em 1955 foi um marco para a constituição da educação matemática no Brasil e contou com a participação de Omar Catunda, catedrático de análise matemática da FFCL-USP (Faculdade de Filosofia, Ciências e Letras da Universidade de São Paulo). Esse congresso também assinalou uma nova etapa da educação matemática na Bahia, que passou a ter contato direto com a matemática moderna, visto que a mesma já estava institucionalizada no ensino universitário em São Paulo e no Rio de Janeiro.

Durante o referido evento, o mesmo teve contato com jovens e recém-formadas professoras baianas (a maioria das pessoas que se formavam na FFCL em matemática eram mulheres) e as convidou para realizar estágios sob a sua orientação. Assim, Arlete Cerqueira de Lima (formada em 1955) foi a primeira bolsista, pelo CNPq, oriunda da Faculdade de Filosofia

\footnotetext{
${ }^{5}$ Martha Dantas realizou estágios na Bélgica, na Inglaterra e na França (DIAS, 2002)
} 
da Bahia, a estudar em São Paulo sob a orientação de Omar Catunda. A experiência formativa vivida pela citada professora também foi crucial para trazer a matemática moderna para a, então, Universidade da Bahia. Após o contato com outra realidade científica e acadêmica, Dias (2012) revela o papel protagonista de Arlete Lima nas mudanças do ensino da matemática na Bahia: inicialmente, no sentido de angariar bolsas de estudos junto ao CNPq para Universidade da Bahia e gestões junto ao reitor Edgard Santos com a finalidade de solicitar a criação de um Centro de Estudos de Matemática na Bahia que funcionasse em paralelo com o Curso de Matemática da FFCL da Bahia.

Como resultado do intercâmbio que Martha Dantas realizou na Europa e do estágio de Arlete Cerqueira de Lima na FFCL-USP, foi fundado em 1960 o Instituto de Matemática e Física (IMF) da Universidade da Bahia. O projeto pretendia a mobilização do ensino e implantação da pesquisa em matemática na UBA. Para completar o quadro de professores do referido Instituto veio para a Bahia, em 1963, o professor Omar Catunda, que passou a coordená-lo a partir do mesmo ano. A criação do IMF, portanto, cumpriu um papel essencial para o avanço do ensino da matemática na Bahia, tanto no sentido de atualizar os egressos da Faculdade de Filosofia quanto o de levar a matemática moderna para as escolas da rede estadual de ensino secundário do estado (DIAS, 2012).

A seguir situamos a trajetória profissional do professor Carloman Carlos Borges, desde o inicio da sua carreira docente, a sua vinda para Feira de Santana e algumas das suas contribuições para a história da educação matemática, principalmente na cidade de Feira de Santana.

\section{Carloman Carlos Borges na história da Matemática em Feira de Santana}

Trabalho realizado por Moreira e Santos (2015), sobre inovação nas práticas educativas de docentes do ensino superior público em Feira de Santana, analisa o papel inovador, segundo a opinião de ex-estudantes, desempenhado pelo professor Carloman Carlos Borges no tocante ao ensino da Matemática, na implantação do ensino superior em Feira de Santana. Ao lado de professores de outras áreas de conhecimento, o referido docente foi um dos pioneiros a dedicar-se à formação de professores na antiga Faculdade Estadual de 
Educação de Feira de Santana (Feefs), posta em funcionamento em setembro de $1968^{6}$. Nessa instituição, que antecedeu a implantação da UEFS, funcionaram os primeiros cursos de formação de professores de "curta duração", em Letras, Estudos Sociais e Ciências, que reunia as formações em Biologia e em Matemática.

Flagramos o registro do ingresso de Carloman Borges na Feefs em documento onde consta a autorização para funcionamento do Curso de Ciências, no Parecer $n^{\circ} 114$ de 24 de agosto de 1970, no trecho em que estão descritos os nomes dos professores que iriam lecionar no curso de Ciências, por área de conhecimento (biologia, física, matemática e educação), acompanhado de uma síntese de currículo. Vejamos:

\section{Matemática}

Carloman Carlos Borges - Diplomado em Matemática pela Universidade de Itajubá em 1968, com pós-graduação igualmente em Matemática pela Escola Federal de engenharia de Itajubá, em 1969, vem ensinando Matemática no Instituto de Matemática da Universidade Federal da Bahia ${ }^{7}$ (In FERREIRA, 2017, p.30).

Mediante o descrito no tópico anterior, a partir do Estado Novo, as Faculdades de Filosofia foram os locais da formação dos licenciados em matemática e, por consequência, da educação matemática. Pelo enunciado acima, verificamos um indício de que o professor Carloman Borges teve sua formação inicial na área de matemática em curso de Engenharia ${ }^{8}$. Contudo, o documento acima transcrito menciona que o mesmo, na ocasião, "vem ensinando Matemática no Instituto de Matemática da Universidade Federal da Bahia”, experiência que o colocaria em contato com a instituição pioneira na Bahia, depois da FFCL, no ensino e na pesquisa nesse campo de estudos.

\footnotetext{
${ }^{6}$ Conforme Santos (2016), tal instituição educacional tinha como principal objetivo suprir a falta de profissionais licenciados em nível superior para atuarem na Educação Básica, principalmente no interior do Estado.

7 Além do nome de Carloman para a disciplina Matemática, constam na Resolução os nomes de mais seis (6) professores que compuseram o quadro de professores: Biologia - Maria Cristina de Oliveira Menezes e Gislaine Vieira Nascimento; Física - Paulo Fernando Simões Lobo; Química - Naides de Cerqueira e Silva de Alves de Lima; Psicologia - Yara Maria Cunha Pires; para Didática - Judite Pires Torres.

${ }^{8}$ Há necessidade de verificação dos diplomas do professor em tela, pois de acordo com o site da Universidade Federal de Itajubá (UNIFEI), a mesma foi criada depois da LDB de 1998. Na década de 60 existia apenas a Escola Federal de Engenharia de Itajubá (EFEI) que oferecia os cursos de engenharia elétrica e engenharia mecânica. Federalizada em 1956, mas adotou a nomenclatura EFEI em 1968, antes disso chamava-se Instituto Eletrotécnico de Itajubá (IEI). Mediante a mesma fonte: "No início da década de 1960, avaliava-se que a escola de Itajubá tinha formado cerca de $40 \%$ do total de engenheiros dessas especialidades existentes no Brasil". In https://unifei.edu.br/apresentacao/historia/, visita em janeiro de 2018.
} 
No que diz respeito à experiência profissional anterior, a análise dos materiais que abordam a sua trajetória apontam que ele exerceu as funções do magistério ainda antes de ingressar no ensino superior, na cidade de Alagoinhas-Bahia, conforme relatou em entrevista publicada no Caderno de Física da UEFS:

Meu interesse pela Matemática nasceu de dificuldades econômicas. Desempregado, em Alagoinhas, em 1958 aceitei dar aulas dessa disciplina no então Ginásio de Alagoinhas. Gostei da experiência e esse gosto se prolonga até hoje... [...] (Entrevista publicada no Caderno de Física da UEFS, 03 (01): 31-41, 2004 p. 32)

Naquela época era comum, que pessoas que cursaram apenas os cursos ginasial ou secundário (ou com cursos conhecidos como de "Madureza", que concedia a habilitação nesses cursos apenas com a realização de provas) exercerem funções docentes nos antigos cursos ginasiais. Aos vinte e seis anos, portanto, Carloman Borges (nascido em 1931) ${ }^{9}$ desempenhou por um ano sua primeira atividade docente, antes de concluir o primeiro ciclo (provavelmente, com curso de Madureza) em um contexto estadual e nacional onde predominava o analfabetismo ${ }^{10}$. O percurso escolar do professor aqui referido demonstra que o mesmo realizou deslocamentos por alguns estados do Brasil, que parecem com as "caminhadas" feitas por alguns militantes do partido comunista, naquele período, de acordo com informações disponibilizadas em jornal de divulgação que aborda a trajetória acadêmica do referido professor:

[...] Carloman estudou a $1^{\mathrm{a}}$ série do $1^{\circ}$ Ciclo (antigo ginásio, atual $6^{\circ}$ ano do Ensino Fundamental) em 1945, na Escola Técnica Comércio de Uberlândia, a $2^{a}$ série na Escola Técnica Comércio de Sergipe, em 1946, e a 3a e 4a séries na Escola Técnica Comércio de Botafogo no Rio de Janeiro, nos anos de 1959 e 1960. Concluiu no ano de 1963 o 2o Ciclo (atual Ensino Médio) na Escola Técnica de Eletrônica Francisco Moreira da Costa em Minas Gerais. (Folhetim de Educação Matemática, março/ abril, 2010, p. 2).

De acordo com Ferreira (2017, p. 29), Carloman foi membro de um grupo de jovens intelectuais comunistas nas décadas de 1940 e 1950, em Aracaju, Sergipe, chegou inclusive a

\footnotetext{
${ }^{9}$ No dia onze de março, na pequena cidade de Frei Paulo, localizada no vizinho estado de Sergipe.

${ }^{10}$ Segundo dados do IBGE, no período em foco, A Bahia era uma das "campeãs" em analfabetismo no Brasil (cf. SANTOS, 2016)
} 
ser preso, por ser o mesmo considerado como de "alta periculosidade", em 1951, quando tinha 20 anos. Período em que abandonou os estudos e somente o retomou em 1959, na Escola Técnica do Comércio de Botafogo (Rio de Janeiro). O autor argumenta que Carloman Borges: "Provavelmente, viveu de forma clandestina, assim como o seu irmão, também comunista, Fragmon Carlos Borges” (p.30). A informação acima destacada corrobora os argumentos desenvolvidos pelo autor, pois maior tempo de permanência do nosso protagonista somente ocorreu no interior de Minas Gerais, quando concluiu o curso superior em 1968 (ano do Ato Institucional $\mathrm{n}^{\mathrm{o}} 5$, o famigerado AI-5).

As perseguições movidas aos comunistas desde a deflagração do golpe civil-militar de 1964 foram muito intensas, diversas lideranças do PCB foram eliminadas fisicamente em operações policiais de "caça aos perigosos comunistas", vivia-se uma situação de terror e de muito medo, sobretudo no momento em que Carloman Borges saiu do interior de Minas para lecionar no Instituto de (IM) da UFBA, a partir de 1970. Ainda de acordo com Ferreira (2017, p.129) a ida para o IM partiu de um convite de Omar Catunda para trabalhar como seu assistente, ao argumentar que seria provável que ambos se conhecessem "em meio as atividades da militância no partido comunista, [...] entre as décadas de1940 e 1950”. Para corroborar sua hipótese o autor expõe as palavras do próprio Carloman, em entrevista publicada no Caderno de Física, que reproduzimos abaixo:

\footnotetext{
Alguns professores e/ou matemáticos me influenciaram. No topo da pirâmide coloco Omar Catunda, com o qual tive uma convivência de sete anos no Instituto de Matemática da UFBa como seu assistente: ele ministrava as aulas teóricas e eu, as aulas práticas (resolução de listas de exercícios) e corrigia as provas elaboradas pelo mestre na avaliação do alunado. [...]. Omar Catunda foi, antes de tudo, um humanista. Com ele era possível conversar acerca dos mais variados assuntos: arte, filosofia, literatura, política e até mesmo, Matemática... Ele teve uma grande influência sobre mim, principalmente quanto a sua dimensão humanística (Caderno de Física da UEFS, Feira de Santana, v. 01, n. 03, p. 31-41, 2004. p. 32-3, In FERREIRA, 2017, p.130)
}

Vemos, assim, que as atividades de docência no ensino superior desenvolvidas por Carloman ocorreram de forma concomitante, apenas com a diferença de pelo menos um semestre a favor da UFBA, em 1970. Diferente da atuação como professor assistente, onde sua atuação limitava-se a ministrar "as aulas práticas (resolução de listas de exercícios) e 
corrigia as provas elaboradas pelo mestre na avaliação do alunado", na FEEFS ele assumiria a exclusiva responsabilidade - evidente que de um lugar privilegiado, enquanto assistente do renomado Omar Catunda. Nesse sentido, a faculdade de Feira de Santana era/seria o seu lugar de poder, no sentido atribuído por Bourdieu ${ }^{11}$, onde Carloman estabeleceu-se como professor e nesta condição viu-se conclamado, juntamente com os demais professores da FEEFS, a realizar o curso de especialização em Conteúdos e Metodologias do Ensino Superior, na Faculdade de Educação da UFBA, em 1974, enquanto exigência do Conselho Federal de Educação (atual CNE), para fins de reconhecimento da Fundação Universidade de Feira de Santana (cujo processo para implantação e reconhecimento fora iniciado em 1970). Em nossa perspectiva a passagem do mesmo pela UFBA foi uma ocasião especial para credenciá-lo como professor universitário ${ }^{12}$ e como precursor da difusão do ensino da matemática em Feira de Santana e região. Esse papel proativo pode ser constatado em depoimento de egressa da FEEFS, quando indagada sobre a existência, ou não, de professores inovadores naquela instituição:

A única inovação foi Carloman [Carlos Borges], que introduziu estudos sobre "instrução programada". O livro era baseado em fichas que complementavam o conteúdo. Acho que ele queria lançar aqui [em Feira de Santana] essa proposta de Omar Catunda e Marta Dantas - quem utilizava a coleção eram os professores que realizavam o curso [a maioria dos alunos era formada por professores da rede de ensino da época]. Foi um projeto que foi utilizado aqui no [Escola] Anísio Teixeira e em escolas em Salvador (na Escola de Aplicação, no Instituto Feminino). Essa inovação não foi do curso, mas trazido por um dos professores. (Entrevistado A4, in SANTOS e REIS, 2013).

De acordo com essa entrevistada que ingressou na FEEFS em 1975, Carloman já participava da oferta de cursos extracurriculares para professores em serviço, pois, na época buscava-se muito uma atualização na chamada matemática moderna, através desses procedimentos de "instrução programada". Embora considerado pelos críticos, dessa modalidade metodológica, como sendo tecnicista, os entrevistados para pesquisa de Santos

\footnotetext{
${ }^{11}$ Cf. o livro Homo academicus, discutido por Joubert Lima Ferreira em sua tese de doutorado, 2017, à página 129 e seguintes, onde elabora em profundidade a discussão sobre as relações estabelecidas por Carloman no âmbito da FEEFS.

${ }^{12}$ De acordo com Santos (2017), muitos professores que participaram da implantação da FEEFS eram licenciados sem experiência e não tinham o ensino superior como horizonte, salvo alguns deles que foram convidados/preparados durante a graduação, ou foram assistentes como no caso de Carloman (algo que estava em desuso com a Lei 5540/68, que extinguia a cátedra).
} 
(2013b) defendem a postura acadêmica desse docente, como pode ser deduzido do depoimento abaixo:

Olha, na sala de aula ele tinha o cuidado de não deixar a gente em dúvida, esclarecia todo mundo. E o que marcava Carloman nas aulas era que ele falava de Filosofia, História e de Pedagogia, do conhecimento. Ele tinha tudo isso junto. Isso que era o diferencial dele. Qualquer conteúdo que ele abordasse ele abordava integrado, buscava o contexto de surgimento daquilo. Mostrava as implicações sociais daquilo. As questões epistemológicas que envolvia aquele conhecimento. O contexto de surgimento, e fazia ligações com outras áreas do conhecimento. Isso ele fazia naturalmente. Era uma abordagem bem erudita, não é. (entrevistado E3 ${ }^{13}$ ).

Na entrevista concedida ao Caderno de Física, o próprio Carloman demonstra um pensamento semelhante sobre si mesmo, vejamos: "Gostei da experiência [de ser professor] e esse gosto se prolonga até hoje... O que me aproxima da Matemática, já que não sou um matemático e sim um simples professor, é a dimensão filosófica, é a sua clarividência, a sua significação - no meu entendimento- mais próxima da "realidade" do que qualquer outra ciência." (Entrevista publicada no Caderno de Física da UEFS, 03 (01): 31-41, 2004 p. 32, in Ferreira, 2017)

A FEEFS foi um laboratório da melhor qualidade para o exercício da prática docente, pois lá os objetivos eram muito claros: formar professores para atuar na escola básica. Ainda nessa instituição, segundo o entrevistado acima, Carloman foi um dos primeiros professores a organizar grupos de estudos com os estudantes e a pensar na oferta de cursos de capacitação para professores em serviço e, posteriormente, cursos de especialização.

Em 1976, com a implantação da UEFS, Carloman já possuía um capital acadêmico e simbólico considerável, ele figura como um dos protagonistas na implantação do Curso de Matemática da Universidade. Assim, no ano seguinte, a implantação da UEFS foi o primeiro professor a solicitar a realização de pós-graduação fora do país, foi para a França onde realizou o doutoramento na universidade de Montpellier II, em 1979 (na época o curso possuía uma espécie de divisão em dois momentos, concedia uma pós-graduação do tipo de mestrado e outro de doutorado, que consistia na elaboração de uma tese). Ao retornar em

\footnotetext{
${ }^{13}$ Acervo da Pesquisa "Pedagogia do ensino superior: trajetória histórica de práticas educativas inovadoras na UEFS", entrevista concedida ao estudante, bolsista de iniciação científica, Jeffersom Moreira (NEPPU)
} 
1979, havia adquirido o honroso, para a época, título de doutor em Matemática, o primeiro da UEFS, num momento em que os cursos de pós-graduação apenas começavam a implantar-se no Brasil, mas com formatação diferente dos da França. Tal título o distinguia da maioria dos colegas, por algum tempo, serviu-lhe também como uma espécie de credenciamento junto à estudantada. Como fizera seu inspirador Omar Catunda, aproximou-se dos jovens, incentivando-os, na organização de grupos de estudos (como mencionaram alguns dos seus ex-alunos na pesquisa sobre inovação, desenvolvida pelo NEPPU) e, ele mesmo criou e institucionalizou o principal deles: o Núcleo de Educação Matemática Omar Catunda (NEMOC) em 1986, que segundo Ferreira (2017, p.130) o mesmo "foi criado num momento de consolidação da Educação Matemática enquanto campo científico, profissional e área de conhecimento".

\section{4. Últimas considerações}

Como conclusão, destacamos, a partir do estudo realizado, que o professor Carloman Borges construiu um legado acadêmico, materializado no NEMOC e a estrutura material que funcionou e/ou funciona em torno do mesmo. Primeiro com uma coluna no jornal Feira Hoje, sob o título "Pergunte que o NEMOC responde", atingia um público maior de interessados nos assuntos do ensino da matemática. Outro legado foi " $O$ folhetim de Educação Matemática”, que era distribuído na rede pública de ensino. Em conformidade com o trabalho de Ferreira (2017), Carloman "[...] foi responsável por mais de 145 artigos publicados pelo Folhetim de Educação Matemática e criou o primeiro curso de Especialização em Educação Matemática da Bahia, em 1999”. (p.130/131). De acordo com essa publicação Carloman:

[...] preocupado com o ensino de Matemática na região, elaborou, promoveu e executou alguns cursos de extensão para professores, bem como para alunos do então curso de Licenciatura em Ciências Habilitação em Matemática. Dentre os cursos realizados, citamos: Trigonometria e Números Complexos (1987), Tópicos de Matemática do $2^{\circ}$ grau (1989) e Introdução ao Cálculo e Análise (1994). (FOLHETIM DE EDUCAÇÃO MATEMÁTICA, 2010, p 03). 
Portanto, conforme já o dissemos, Carloman Carlos Borges criou uma estrutura que preserva sua memória como o primeiro professor universitário de matemática da cidade de Feira de Santana e região.

\section{Referências}

DIAS, André Luís Mattedi. Engenheiros, mulheres, matemáticos: interesses e disputas na profissionalização da matemática na Bahia (1896-1968). 321 f. Tese (Doutorado em História Social), Universidade de São Paulo, São Paulo. 2002.

DIAS, André Luís Mattedi. Uma história da Educação Matemática na Bahia. In: SANT’ANA, C. C.; SANTANA, E. R. S.; NUNES, C. B. (org.). Educação Matemática na Bahia: panorama atual e perspectivas. Itabuna: Via Literarum, 2012. p. 13-34.

FERREIRA, Joubert Lima. Fios, retalhos e pontos: tecituras sobre a profissionalização docente em matemática em Feira de Santana (1970-1991). 172 f. Tese (Doutorado), Universidade Federal da Bahia, Programa de Pós-Graduação em Educação, Salvador, 2017.

SANTOS, A. M. F. Uma aventura universitária no sertão baiano: da Faculdade Educação à Universidade Estadual de Feira de Santana. Feira de Santana: UEFS Editora, 2016.

SANTOS, Ana Maria Fontes dos; REIS, Nayara Tainã Andrade. Percepções de egressos de cursos de formação de professores sobre práticas pedagógicas inovadoras de docentes da Faculdade Estadual de Educação de Feira de Santana (1968-1976). VII Colóquio Internacional Educação e Contemporaneidade, realizado no período de 19 a 21 de setembro de 2013 no Campus Prof. José Aloísio de Campos - UFS, São Cristóvão (SE). 